\title{
Motu
}

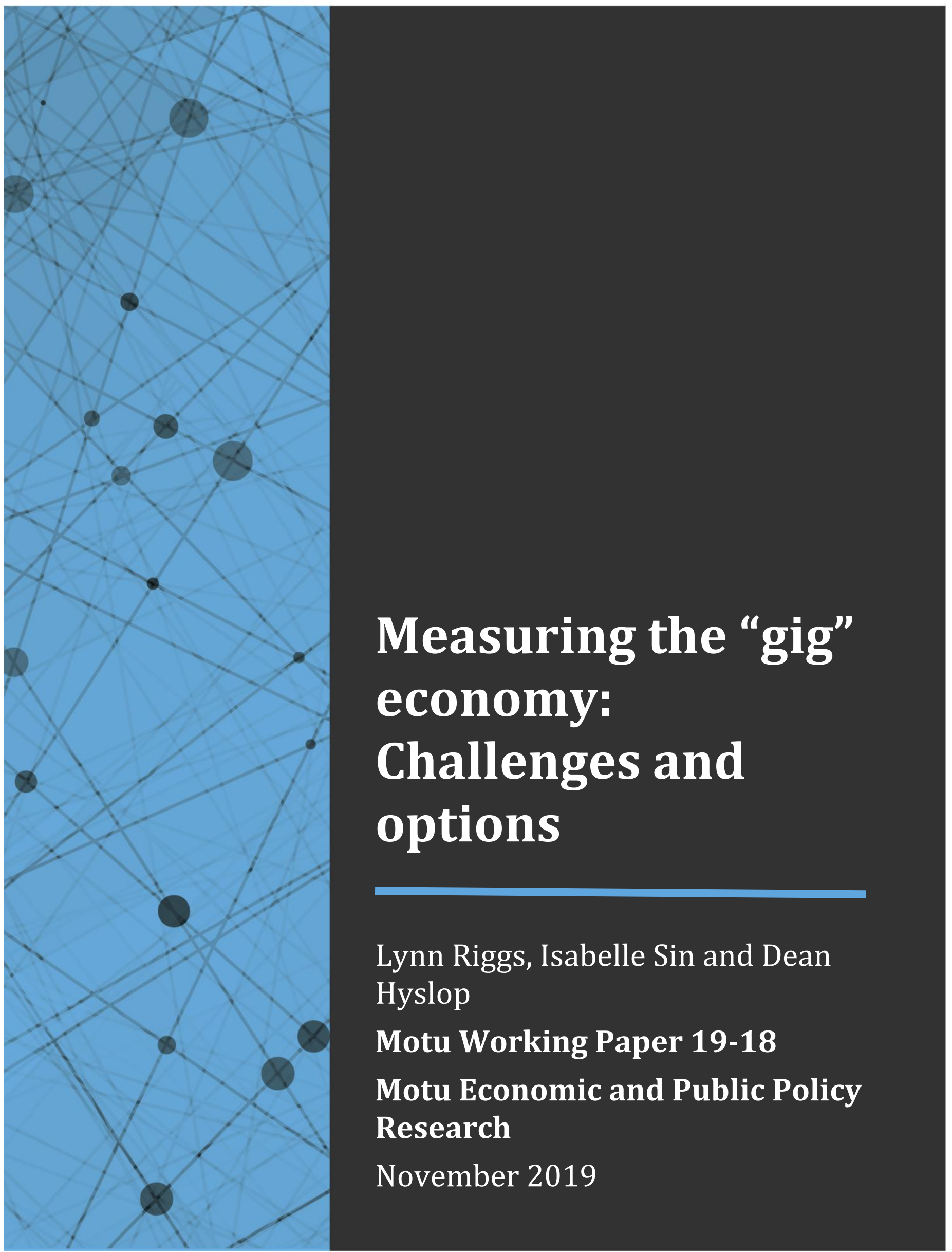




\section{Document information}

Author contact details

Lynn Riggs

Motu Economic and Public Policy Research

lynn.riggs@motu.org.nz

Isabelle Sin

Motu Economic and Public Policy Research

isabelle.sin@motu.org.nz

Dean Hyslop

Motu Economic and Public Policy Research

dean.hyslop@motu.org.nz

\section{Acknowledgements}

This research was supported by the Productivity Commission. We thank Judy Kavanagh and John MacCormick for helpful discussion and comments on the research.

Motu Economic and Public Policy Research

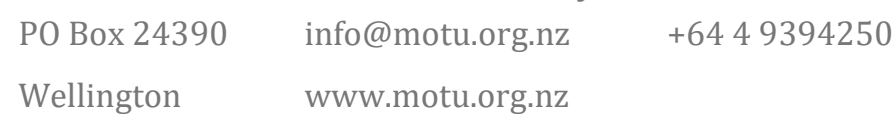

New Zealand

(C) 2019 Motu Economic and Public Policy Research Trust and the authors. Short extracts, not exceeding two paragraphs, may be quoted provided clear attribution is given. Motu Working Papers are research materials circulated by their authors for purposes of information and discussion. They have not necessarily undergone formal peer review or editorial treatment. ISSN 1176-2667 (Print), ISSN 11779047 (Online). 


\section{Abstract}

The increase in internet-based services has raised policy interest in gig work, which is work done outside formal employer-employee relationships. Given the dearth of information about the nature and magnitude of gig work and the extent of its growth in New Zealand, it is unclear whether current regulatory institutions adequately regulate it. There is also concern among policymakers about the effect of gig work on the financial stability of gig workers. In this paper we provide a New Zealand-specific typology for identifying gig work, and discuss conceptual and practical issues related to measuring it. We describe how existing New Zealand data can be used to learn more about gig work and make suggestions for improving its measurement in the future.

JEL codes

J21，J40，J46， J81， J83，J88

\section{Keywords}

Gig work, Gig economy

\section{Summary haiku}

Is gig work growing?

What do we know about it?

More data will help. 


\section{Table of Contents}

$1 \quad$ Introduction

2 Background 2

$\begin{array}{lll}2.1 & \text { Understanding gig work }\end{array}$

$\begin{array}{lll}2.2 & \text { Policy interest in the gig economy } & 5\end{array}$

2.3 Classifying types of work in New Zealand $\quad 6$

3 Defining gig employment $r$

$4 \quad$ Measuring gig employment $r$

$\begin{array}{lll}4.1 & \text { Literature on measuring gig employment } & 13\end{array}$

\begin{tabular}{ll}
4.2 & Different answers from different measures \\
\hline
\end{tabular}

$\begin{array}{lll}4.3 & \text { Recommendations for measures of gig work and the gig economy } & 20\end{array}$

$\begin{array}{lll}4.4 & \text { Data currently available in New Zealand } & 21\end{array}$

$\begin{array}{llr}4.5 & \text { Next steps } & 29\end{array}$

5 Conclusions $\quad 30$

$\begin{array}{lr}\text { References } & 31\end{array}$

$\begin{array}{lr}\text { Recent Motu Working Papers } & 33\end{array}$

\section{Tables and Figures}

Figure 1: Self-employment rates using US household survey and administrative data 18

Figure 2: Trends in US self-employment: household survey data vs. administrative data 19

Figure 3: Self-employment in New Zealand using HLFS 22

Figure 4: New Zealand employment types using HLFS 23

Figure 5: New Zealand businesses by business type using business demography statistics 25

Figure 6: New Zealand zero-employee businesses using business demography statistics 26

Table 1: US work arrangement types and characteristics 3

Table 2: New Zealand work arrangement types and characteristics $\quad 7$ 


\section{Introduction}

The increasing use of internet-based services in recent years has raised policy interest in the potential growth in employment that is done outside of formal employer-employee relationships. ${ }^{1}$ Such non-formal work, performed on-demand and with no expectation of an ongoing relationship, is commonly termed "gig work", and the broader institutional setting in which gig work occurs is referred to as the "gig economy". There is considerable concern about the adequacy of existing labour market and other related regulatory institutions associated with the gig economy, as well as the possible implications for the labour market outcomes of workers involved in gig work. For example, there is potential risk for the sustainability and viability of New Zealand's tax revenue collection system and of ACC institutions in the face of increasing gig work. Similarly, there are concerns around the employment and earnings prospects of gig workers, with possible flow on effects to the welfare system and workers' ability to accumulate adequate retirement savings.

However traditional employment measures do not necessarily capture gig work well, and so relatively little is known about the extent of gig work in New Zealand, its recent growth, potential future growth, or the likely policy implications. This paper provides a New Zealandfocused review of these issues.

We begin in the next section by discussing the background to, and policy interest in, gig work and the gig economy. There are at least two important issues to consider for the policy implications associated with any growth in gig work. First, it is important to understand the extent to which growth in gig work represents new or 'additional' work in the economy as opposed to substituting for existing work, particularly that done within formal employeremployee relationships. New work may occur either from changes in workers' labour supply or from changes in employers' labour demand. For example, to what extent does the work created by Uber increase employment by adding new drivers to the labour force (e.g., students, retirees) rather than simply substituting away from regulated taxi services? Second, it is important to consider behavioural responses on the part of either employers or workers to possible incentives in the regulatory settings. For example, in the case of Uber, to what extent is the increase in gig work driven by arbitrage opportunities associated with the high burden of regulation in the taxi industry? We also review the international literature that documents characteristics of gig work commonly used to distinguish gig work from other forms of employment, and discuss how these differ in the New Zealand context.

In section 3 we discuss alternative approaches to defining gig work, since this poses the largest challenge to measuring the gig economy and is a fundamental component of doing so. We

\footnotetext{
1 Of course, this type of arrangement includes casual employees and labour-hire worker arrangements that long predate the existence of the internet.
} 
also discuss the distinction between 'gig work' and the 'gig economy', which can include non-gig work that provides the institutional support for gig work.

Section 4 focuses on measurement issues. In this section, we review the literature on measuring gig work, discuss alternative survey and administrative data sources, and consider the data availability in New Zealand. The paper ends with a few concluding remarks in section 5 .

\section{Background}

In this section we first outline the origins of the term "gig work", and discuss the characteristics of gig work that distinguish it from formal employer-employee relationships. We then discuss the reasons for policy interest in the gig economy; and finally discuss the types of work arrangement that exist in New Zealand and characterise their differences.

\section{$2.1 \quad$ Understanding gig work}

The term "gig" comes from the music industry, where independent musicians would record one song or play in one performance with no expectation of future work (Abraham et al. 2018). In the early days of the term "gig economy", it tended to refer to work obtained through an online platform (e.g., Uber) with work doled out in bits and pieces. ${ }^{2}$ However, more recently, the term gig work has become associated with or representative of alternative, less structured work arrangements with a specific focus on non-employees. These alternative arrangements have received increased scrutiny recently due to a perception that new technologies (e.g., online platforms) are accelerating changes in the way work is organised and also due to the implications that these more precarious work arrangements have for workers. Moreover, there is concern that the regulatory landscape has not kept up with the technological advancements, which have given these new companies an unfair advantage over their traditional competitors, which are governed by existing regulations (Davidson and Infranca, 2016). ${ }^{3}$

In the literature these types of alternative work arrangements are referred to using a variety of terms, including informal, precarious, non-traditional, or contingent work, and the term gig work is used with varying shades of meaning. In fact, only one paper, Abraham et al. (2018), appears to explicitly define gig work, and in so doing establishes a typology for different work arrangements that shows those types the authors consider to be gig worker arrangements (i.e., independent contractor/freelancer, and on-demand/platform worker). This matrix, reproduced in Table 1, is a useful basis for thinking about which types of work arrangements and which specific characteristics distinguish gig work from other types of work.

\footnotetext{
2 In the literature, this is also referred to as the sharing, online platform, or on-demand economy.

${ }^{3}$ Uber and AirBnB are two key examples. Uber avoided fairly stringent regulations to which hackney services were subject, and AirBnB avoided many of the taxes and other regulations required of traditional hoteling services.
} 
Table 1: US work arrangement types and characteristics

\begin{tabular}{|c|c|c|c|c|c|c|}
\hline \multirow[b]{2}{*}{ Work Arrangement Type } & \multicolumn{6}{|c|}{ Work Arrangement Characteristic } \\
\hline & $\begin{array}{c}\text { Paid wage or } \\
\text { salary } \\
\end{array}$ & $\begin{array}{l}\text { Implicit or } \\
\text { explicit contract } \\
\text { for continuing } \\
\text { relationship } \\
\end{array}$ & $\begin{array}{c}\text { Predictable work } \\
\text { schedule }\end{array}$ & $\begin{array}{c}\text { Predictable } \\
\text { earnings when } \\
\text { working } \\
\end{array}$ & $\begin{array}{c}\text { Work supervised } \\
\text { by firm paying } \\
\text { salary }\end{array}$ & Gig worker \\
\hline \multicolumn{7}{|l|}{ Employee } \\
\hline Traditional & Yes & Some & Yes & Yes & Yes & No \\
\hline On-call/varying schedule & Yes & Some & No & Yes & Yes & No \\
\hline Direct-hire temporary & Yes & No & Yes & Yes & Yes & No \\
\hline \multicolumn{7}{|l|}{ Contract company worker } \\
\hline Temporary help agency & Yes & Some & Yes & Yes & No & No \\
\hline Prof. employer organization (PEO) & Yes & Some & Yes & Yes & No & No \\
\hline Other contract company worker & Yes & Some & Yes & Yes & No & No \\
\hline \multicolumn{7}{|l|}{ Self-employed } \\
\hline Business Owners & & & & & & \\
\hline Incorporated & Some & Some & Yes & Some & $\mathrm{N} / \mathrm{A}$ & No \\
\hline Partner & No & Some & Yes & Some & $\mathrm{N} / \mathrm{A}$ & No \\
\hline Unincorporated sole proprietor & No & Some & Yes & Some & $\mathrm{N} / \mathrm{A}$ & No \\
\hline Independent contractor/freelancer & No & No & No & No & $\mathrm{N} / \mathrm{A}$ & Yes \\
\hline Day labourer & No & No & No & No & $\mathrm{N} / \mathrm{A}$ & Yes \\
\hline On-demand/on-line platform worker & No & No & No & No & $\mathrm{N} / \mathrm{A}$ & Yes \\
\hline
\end{tabular}

Source: Abraham et al. (2018). 
The work characteristics to distinguish traditional employment from other types of work arrangements used in Abraham et al. (2018) include the following:

- the person is paid a wage or salary,

- the work relationship is expected to continue, ${ }^{4}$

- the work schedule is predictable,

- earnings are predictable when working, and

- on-the-job supervision is provided by the firm paying the worker's salary.

Abraham et al. (2018) assert that gig workers are among the unincorporated selfemployed who are not paid a wage or salary, do not have an implicit or explicit contract for continuing the work relationship, and do not have a predictable work schedule or earnings. It is important to note that Abraham et al. (2018) do not define gig work in relation to an online platform as gig work is not always mediated by a platform, though gig work and platform work are often conflated. ${ }^{5}$ For example, in Ireland and the UK, the term "gig" economy generally refers to app-based services done on demand and on location, though in other countries, such as Italy, Finland and Austria, the term "gig economy" is used more in line with the use by Abraham et al. (2018) (Eurofound 2018).6

In New Zealand, the line between employee and non-employee appears to be more clearly drawn than in the US (upon which Abraham et al. (2018) is based). Businesses in New Zealand employ labour either as employees or as contractors (Hall and Fussey 2018), with the difference between the two categories driven by legal tests developed by the courts that are related to the nature of the work performed.7 The legal distinction in New Zealand is applied to ensure the rights of employees provided under employment law are not violated. ${ }^{8}$ In New Zealand, employees are legally required to be covered by a written employment agreement that outlines the terms of their employment and have minimum rights that include holiday and leave entitlements, payment of a wage at or above the legal minimum, KiwiSaver employer subsidies, dismissal protections, and the right to take a personal grievance. Employers must also pay ACC levies based on their employees' annual earnings, and employers send payroll tax withholdings

\footnotetext{
4 This is used by the US Bureau of Labor Statistics for its definition of contingent work.

${ }^{5}$ Eurofound (2018) characterises platform work as paid work, organised through on online platform, with jobs that are broken down into specific tasks that are outsourced or contracted out and provided on demand. They also note that the term "gig economy" is used differently in different European countries but that in a number of countries the gig economy also used in place of the term "platform economy".

${ }^{6}$ Even amongst these countries, the term "gig economy" is used slightly differently - in Italy, gig work generally refers to precarious work, but in Germany, it generally refers to menial tasks. (Eurofound 2018)

${ }^{7}$ In New Zealand, courts or labour inspectors will look through the formal contracts and other documentation to determine the fundamental nature of the employment relationship in deciding if a worker should be considered an employee or contractor. In NZEmpC 150 Prasad v LSG Skychefs Ltd, an employment court in 2017 found the plaintiff to be an employee of Skychefs despite being employed and paid by a subcontracting labour-hire firm because Skychefs acted substantively as the plaintiff's employer as measured along a number of dimensions, including the fact that on-the-job supervision was done by LSG and not the labour-hire firm. For the full judgement, see https://employmentcourt.govt.nz/assets/Documents/Decisions/2017-NZEmpC-150-Prasad-v-LSG-Sky-ChefsLtd.pdf. See the Employment New Zealand website for more information about these tests: https://www.employment.govt.nz/starting-employment/who-is-an-employee/difference-between-a-self-employedcontractor-and-an-employee/

8 These include the Employment Relations Act 2000, the Minimum Wage Act 1983, and the Holidays Act 2003.
} 
directly to IRD on their employees' behalf (PAYE). ${ }^{9}$ These rights and benefits generally apply to both full- and part-time employees, including casual employees. However, some of these rights do not apply to newly hired employees. For example, employees are only entitled to sick leave if they have been employed continuously for six months with the same employer. In contrast, contractors - and the self-employed more generally - do not receive these protections and entitlements. Hence, gig workers, defined as the unincorporated self-employed, will generally not have these protections either.

\subsection{Policy interest in the gig economy}

There are several reasons for policy interest in gig work. First, if gig work increases at the expense of more permanent employment without improving worker protections, risks and costs would shift from employers to workers. Instead of employers facing the risk that they will have to pay the salary of employees whose labour is not currently required, workers bear the cost of variable hours and income, and face the risk that demand for their work will fall in the future. This may be inefficient as workers are likely to be more risk averse and have less ability to pool risk. In fact, a number of surveys have found that many gig workers would prefer to have traditional jobs. In New Zealand in 2018, Statistics New Zealand reported that slightly more than half of temporary workers preferred a permanent job and that the most frequently given reason for working in a temporary job was because no other work was available. ${ }^{10}$ However, gig work has benefits for some workers, allowing them more flexibility or autonomy, and may create new activities and opportunities. ${ }^{11}$ Even so, the expansion of this type of work to a large number of workers without adequate protections may undermine the social safety net provided to offset the negative effects of a downturn and may be inefficient if workers underestimate the risks these arrangements pose.

Second, government revenues from GST could also be impacted by an increase in gig or informal work. According to the Goods and Services Tax Act 1985,12 the self-employed in New Zealand only need to register for GST if they carry out taxable activity and the total gross value from their sale of goods or services is $\$ 60,000$ or more in the last 12 months (with some minimal exceptions) or if their prices include GST. Hence, if gig work means that the sale of goods and services are distributed across more individuals or entities to the extent that the GST

\footnotetext{
${ }^{9}$ In some cases, businesses will also send payroll tax withholdings directly to IRD on their contractors' behalf. Moreover, in New Zealand, the effective tax and ACC rates are similar for employees and contractors, so there are not the same incentives to misclassify workers as there might be in other countries. One concern, however, is that workers may not realise or be told that they are liable for ACC levies.

10 These results are based on the 2018 Survey of Working Life. For more information, see https://www.stats.govt.nz/reports/survey-of-working-life-2018.

11 Abraham et al. (2018) provide a more complete summary of the positives and negatives of gig work for both workers and businesses.

12 See s51(1)(a) in http://www.legislation.govt.nz/act/public/1985/0141/latest/whole.html.
} 
registration threshold is crossed less often, less GST may be paid.13 Current research from other countries indicates that most gig workers' incomes likely fall well below this threshold. For example, Collins et al. (2019) find that most online platform workers in the US gross less than US $\$ 2,500$ annually.

Without accurate measures of the gig economy, it will be difficult to monitor changes in its impact on the aforementioned issues as well as on other aspects of the economy. Hence, it is important to understand how gig workers and the value of their labour may be missed by traditional measures of economic activity, especially since current research indicates that this is the case.

Third, if gig work becomes a more significant component of the economy, missing this activity in traditional measures of economic activity has additional implications for monitoring the economy overall. For example, Bracha and Burke (2016) find that the employment rate in the US in 2015 would have been 2.5 percentage points higher and the labour force participation rate (LFPR) 2 percentage points higher if all informal workers were classified as employed. Restricting this to informal workers with at least 20 hours of informal work per week would still mean a 0.5 percentage point increase in the 2015 US employment rate and a 1 percentage point increase in the LFPR. This has further implications for accurately measuring labour productivity, multifactor productivity, output, and gross domestic product.

\subsection{Classifying types of work in New Zealand}

We now classify various work arrangements in New Zealand to help identify possible gig work, and characterise their differences. In New Zealand, workers may be employed either directly by the employer for which the work is done ("direct-hire" workers), indirectly through a third party labour-hire company ${ }^{14}$ ("indirect-hire" workers), or as self-employed contract workers.

In Table 2, we modify Abraham et al.'s (2018) Table 1 to better reflect the New Zealand context. This table shows which types of workers may be affected by the various concerns related to gig work, providing a better understanding of where these risks may be concentrated. There is still a split between employees and the self-employed, but one work characteristic has been revised - "Implicit or explicit contract for continuing relationship" - since all employees are required to be covered by a written employment agreement. It has been replaced with "the relationship is expected to continue indefinitely".

\footnotetext{
13 There are, however, reasons why an individual or entity may still register for GST before the threshold has been crossed (e.g., claim back GST on purchases or business set-up costs).

14 These companies may also be referred to as temporary help agencies, "temp" agencies, or recruitment agencies.
} 
Table 2: New Zealand work arrangement types and characteristics

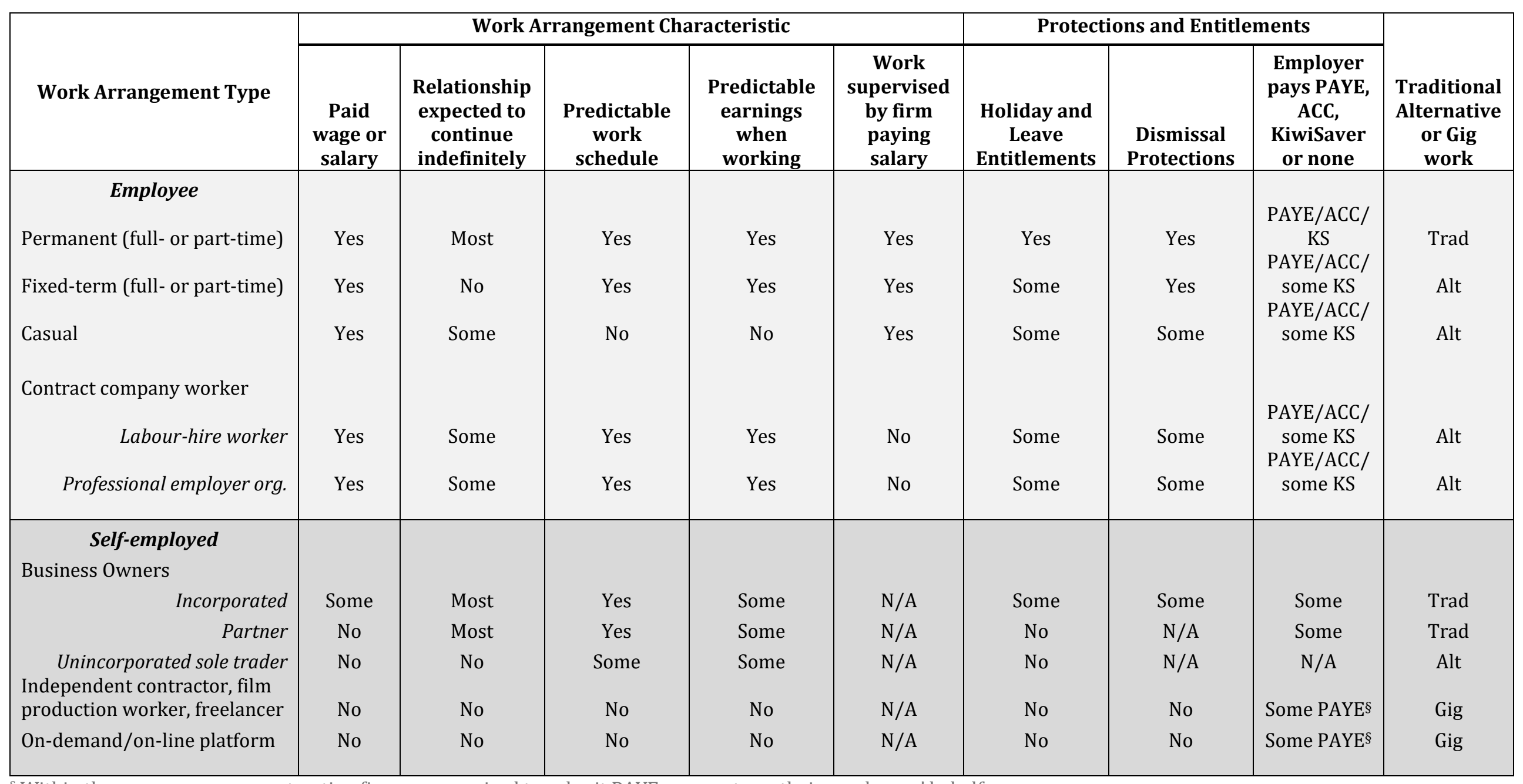

§ Within these groups, some contracting firms are required to submit PAYE payments on their employees' behalf.

Source: Based on Abraham et al. (2018) but updated for NZ context using Employee vs Contractor: Know the Difference from Employment New Zealand: https://www.employment.govt.nz/starting-employment/who-is-an-employee/difference-between-a-self-employed-contractor-and-an-employee/ 
The new table has additional columns to show which workers are covered by the following protections and entitlements:

- Holiday and Leave Entitlements,

- Dismissal Protections,

- Employer payment of PAYE tax, ACC levies, KiwiSaver employer contributions.

Direct-hire employees may be employed on either a permanent, fixed-term, or casual basis, but are required to have written employment agreement in each case. Permanent employees in New Zealand are most similar to "traditional employees" in Table 1. They are paid a wage or salary and have predictable earnings and hours, and their work is supervised by the firm that is directly paying their salary. In particular, employers are required to send PAYE payments to IRD, submit levies to ACC, and make employer contributions to KiwiSaver on their employees' behalf. Moreover, permanent employees generally receive at least the minimum entitlements, protections, and benefits required under the law regardless of whether they work full- or part-time.

Fixed-term employees in New Zealand are similar to US direct-hire temporary employees listed in Table 1; however, in New Zealand, employers must have a "genuine reason based on reasonable grounds" for not making the position permanent, and the employee must be told of this reason. Fixed-term employees include seasonal workers, who can be re-hired at the start of every season. Fixed-term employees with less than 12-month terms are also less likely to receive the full entitlements and benefits provided to permanent employees as these often have some minimum term requirements (e.g, sick or bereavement leave). Moreover, even though fixedterm employees have dismissal protections for the term of the employment agreement, there is no expectation of employment beyond that term. Given the lack of permanency of these positions, we classify this type of work arrangement as alternative or contingent (shown in the last column of Table 2).

Casual employees in New Zealand, are employees with no guaranteed hours, regular pattern, or ongoing expectation of work. Despite this, casual employees are still expected to have a written employment agreement and to have some protections and entitlements, although the way in which these are applied will vary. This type of employment is the most precarious of the three types of employees (permanent, fixed-term, and casual), as each time an employee accepts an offer of work it is treated as a new period of employment. Given the lack of permanency of these positions and the unpredictability of work, we classify this type of work arrangement as alternative or contingent (shown in the last column of Table 2).

Most workers in New Zealand are direct-hire employees working for the employer that pays them. However, businesses may also contract with other businesses for additional indirecthire workers (either on a short- or long-term basis) rather than directly hiring employees 
themselves. The main difference in this scenario is that while employees work directly for the labour-hire company, the client business supervises and controls their work. In New Zealand, these work arrangements are also known as triangular employment arrangements. While these employees should be afforded similar legal protections as other employees, additional protections are being considered by Parliament that would allow these workers to raise a personal grievance against the business supervising their work. ${ }^{15}$ Moreover, these arrangements are designed to give the client firm more flexibility and so tend to be temporary and precarious in nature, and hence, are classified as alternative or contingent.

The lower section of Table 2 applies to self-employed workers in New Zealand. In general, business owners tend be thought of as part of the traditional and permanent labour pool. This is particularly true for owners of incorporated businesses and partnerships with an established clientele that provides fairly predictable work. Unincorporated sole traders straddle the line between the more traditional type of work arrangement and the more precarious nature of work facing the other types of self-employed, which include independent contractors, freelancers, film production workers, and on-demand or on-line platform workers. Abraham et al. (2018) indicate that independent contractors and freelancers could be categorised as unincorporated sole traders, but their rationale for separating them is that independent contractors and freelancers may not identify as owning a business. In Table 2, unincorporated sole traders are listed separately from these other types of self-employment, but they have many similar characteristics. These traders are classified as alternative or contingent because they straddle this line, whereas independent contractors, freelancers, film production workers, and ondemand or on-line platform workers are all classified as gig workers as their employment generally consists of one-off jobs done on a temporary basis.

While many measures of the gig economy have been in line with the definition developed by Abraham et al. (2018) and focused on gig workers themselves, Kenney et al. (2018) note that to comprehensively measure the contribution of gig work to the economy as a whole would require counting the labour of workers employed by the platforms supporting the gig economy, without whose work the gig economy could not function. Many of these workers are not themselves gig workers; in fact, they may be any of the types of employees shown in Table 2. For example, the firm that develops and runs the platform that intermediates gig work is likely to use both direct employees and contract workers. Employment then generated by the platform itself may also be filled using different types of work arrangements. Hence, a broader measure of the gig economy that includes gig work as well as the work done to support its intermediation

\footnotetext{
15 This is the Employment Relations (Triangular Employment) Amendment Bill. For further information about the bill, see https://www.parliament.nz/en/pb/bills-and-laws/bills-proposed-laws/document/BILL_76281/employmentrelations-triangular-employment-amendment
} 
(e.g., supporting the platform) may be needed for different types of questions; ${ }^{16}$ however, this is a departure from what has generally been done in the literature.

Kenney et al. (2018) also classify platforms into three types based on what the platform mediates - work, content creation, or funding - with platforms mediating work being those that are most often associated with gig work. According to this breakdown, platforms mediating work include platform-mediated marketplaces (e.g., eBay, Etsy), in-person service provision (e.g., Uber, GrubHub), or remote service provision (e.g., Upwork, Fiverr, Working Nomads). This could also be a useful typology for identifying specific components or industries within the gig economy.

Eurofound (2018) provides a typology for defining different types of platform work based on the following characteristics: skill level (low, medium, or high); service provision location (online or on-location); scale of tasks (micro tasks or larger projects); job award selection process (selection of provider determined by platform, client, or worker); and matching form (offer or contest). These characteristics could be used to further classify gig workers within the broader category. For example, the Eurofound (2018) analysis uses this typology to then compare and contrast work arrangements for three types of platform work: on-location, platform-determined work (generally low-skilled); on-location, worker-determined work (generally low to moderately skilled); and online contest work (generally high skilled). However, there is some overlap between these characteristics and those already used to distinguish gig work from traditional work (e.g., the job award selection process can be a proxy for the extent of control the worker has over the work that is being done).

\section{Defining gig employment}

Abraham et al. (2018) is the only paper we are aware of that explicitly defines gig employment in a way that is distinct from their measures or the underlying data used in the analysis. They define gig employment as "one-off jobs on which workers are paid for a particular task or for a defined period of time." Hence, they contend that this corresponds to work arrangements where gig workers are not paid a wage or salary, the relationship is not expected to continue indefinitely, and both earnings and hours are unpredictable. Other papers discuss measuring the gig economy but do not necessarily define it as such. In general, these papers end up measuring the self-employed or some subset of the self-employed.

As we will show in the following sections, measuring the gig economy is difficult because it is so amorphous. Using the Abraham et al. (2018) definition of gig employment is a good basis

\footnotetext{
16 Not all platform work would be included in this component - only those platforms that mediate or facilitate gig work. For example, platform work for eBay is likely to be excluded, whereas platform work for Uber would be included. From a policy perspective, one could argue that policies that affect gig work are also likely to affect employment in the platforms that support or mediate gig work. Hence, in some circumstances, including this component would be important.
} 
for measuring the gig economy, but on its own, it would miss, for example, the additional activity generated from the development and maintenance of the platforms used for mediating the work as discussed in Kenney et al. (2018). ${ }^{17}$ It also does not include any mention of online- or platform-mediation. Hence, one might think about measuring various aspects of the gig economy and determining its boundaries using narrower and broader definitions. The Bureau of Labour Statistics, for example, produces three measures of contingent work with each additional measure broadening the definition (Polivka 1996).

A similar methodology to that used for contingent work could be developed for the gig economy using a very narrow definition with multiple dimensions as the base (e.g., platformmediated low-skill gig work) and broadening from there. Given that the literature around gig work has been largely motivated by platform-mediated work, this seems to be an important subcomponent of the gig economy. A second dimension of the definition could relate to the "defined period of time" of each task or job as workers on longer term contracts (e.g., 6-month) may be closer on the spectrum to fixed-term or even full-time employees. Characteristics used in Eurofound (2018) - e.g., skill level, scale of tasks - could also provide dimensionality to the broader measures of the gig economy. However, it is important to note that the literature does not generally limit the definitions of gig work to low-skill or very short duration work, though various measures used in the literature may have differentiated gig work based on these factors because there may be different welfare implications. For example, low-skill gig workers may be less able to respond to or recover from negative shocks than high-skill gig workers as lowskilled tasks generally garner low rates of pay due to high levels of competition (Eurofound 2018). A challenge in using some of these dimensions, however, is developing effective measures that adequately distinguish these different types.

Moreover, measuring the extent of gig employment should not be limited to a simple count of the number of people engaged in gig work - it should also include measures of the extent to which people are engaged (e.g., number of hours, percent of total income) as well as the total value of gig work.

Measuring the labour income for any self-employed person is difficult because labour income is often combined with return on investment or economic profit (Krueger 1999; Gollin 2002; Freeman 2011; Gomis 2019). This is true for gig work as well, especially as some portions of the gig economy may be more capital intensive than others. AirBnB is a classic example since the revenue generated through AirBnB depends on the quality and location of the accommodations provided. Moreover, some AirBnB owners may do much of the labour themselves (e.g., cleaning the space, stocking food items, booking activities for customers),

\footnotetext{
17 If the reason for measuring the gig economy is to ensure that a hard-to-capture (and potentially growing) segment of the economy is being measured, then including this component of the gig economy is not necessary because this type of work should be captured in more traditional measures.
} 
whereas other owners may outsource these activities. Hence, at a minimum, net income measures are needed.

Even if net income from the business is available, determining the labour share of the selfemployed can be complicated. Two methods are commonly used to determine the labour income for the self-employed: one uses a fixed share to divide the income between labour and capital, ${ }^{18}$ while the other imputes self-employed income using the average income of similar employees. ${ }^{19}$ The fixed-share method is typically used with aggregate data (e.g., national accounts data), whereas the imputation method is used with microdata where more detailed information about the self-employed is generally available.

The following section provides a review of the various methods and measures that have been used to measure the gig economy as well as a discussion of the limitations of these measures.

\section{$4 \quad$ Measuring gig employment}

The data used to study the gig economy previously have come from three main sources: household survey data, government administrative data, and private business data. Each of these sources has limitations. Household surveys, for example, may not probe sufficiently to uncover household members' work arrangements in general, and particularly if reported by a proxy respondent, especially when the work is informal and may not necessarily be thought of as a job, ${ }^{20}$ or when the arrangement resembles a traditional employee arrangement but would actually be reported as independent contracting or freelancing by the worker. Administrative (i.e., tax) data is also limited in that there can be underreporting especially for non-employee work arrangements. ${ }^{21}$ Private business data have generally come from the online platforms themselves, but have also included financial records from financial institutions. These data are limited in their coverage and may not be generalizable to the overall population. For example, data from one online platform only includes workers from that platform and generally has very limited information about the workers themselves. Moreover, as platforms enter and exit the market, it becomes increasingly difficult to ensure that the data are comprehensive, representative, or consistent over time. Farrell, Greig, and Hamoudi (2018) discuss that the

\footnotetext{
${ }^{18}$ Krueger (1999) discusses the fixed-share methodology typically used with the national accounts data in the US, with the common convention being to allocate two-thirds to self-employed income labour income and one-third to capital in aggregate.

19 This imputation method can simply use the average employee wage, but using a more robust set of employee characteristics is generally preferred. These characteristics typically include age, educational attainment, industry, and sex. (Collins et al. 2019; Freeman 2011; Gomis 2019)

${ }^{20}$ Abraham and Amaya (2018) discuss this topic in detail.

21 In most countries and in most cases, the self-employed are responsible for paying their income tax based on their self-reported earnings to the government. In the US where a fair amount of research in this area using administrative data has been done, sole proprietors are required to file a "Schedule C" to accompany their main tax form and businesses are required to file a 1099 form to report business-to-business payments. In New Zealand, there are different ways to identify the self-employed using tax filings. These are outlined in Fabling and Maré (2015).
} 
number of platforms used in their analysis increased from 42 to 128 between June 2016 and March 2018, and all but 12 of the original 42 platforms acquired or were acquired by another company requiring additional effort to maintain consistency over time.

\subsection{Literature on measuring gig employment}

While there are a number of papers that discuss the gig economy, there are relatively few that actually attempt to measure the gig economy or some aspect of it. Even when studies attempt to measure the gig economy, they generally rely on some measure of the self-employed and usually with the intention of determining if gig work appears to be an increasing phenomenon. Hence, many papers are more interested in estimating the trend than the actual level of gig work. Moreover, many of these papers have focused on estimating the number of gig workers and few have included measures in terms of total monetary value.

Lawrence Katz and Alan Krueger intended to conduct the first nationally-representative estimate of the percent of workers in the gig economy when they contracted with the RAND institute in 2015 to survey people in the US about alternative work arrangements with core questions based on the Bureau of Labour Statistics (BLS) Contingent Work Supplement (a supplement to the Current Population Survey) (Katz and Krueger 2016). They use this supplement as a basis for their survey because the supplement was specifically developed to measure contingent work, which has an indefinite nature similar to gig work as BLS defined it in 1989: "any job in which an individual does not have an explicit or implicit contract for long-term employment" (Polivka 1996, 4).22

The key to determining if work is contingent is to determine if the job is expected to continue or if the job is indeed temporary (Polivka 1996). The Contingent Work Supplement (CWS) does this using two initial questions: the first asks if the respondent's job is temporary (only for a limited time or until the completion of a project) and the second asks if the respondent could continue with their current employer as long as the respondent wished (given no change in economy or inadequacy in job performance). The CWS assesses whether the temporary nature of the job is due to the respondent's personal reasons (e.g., a college student going back to school at the end of the summer). The CWS also measures workers in alternative work arrangements - independent contractors, on-call workers, workers paid by temporary help agencies, and contract company workers (Polivka 1996).

Using the CWS alternative work arrangement classifications from the RAND survey, Katz and Krueger (2016) estimate the percentage of individuals who were employed in alternative work arrangements at 15.8 percent of US workers in 2015 (up from 10.7 percent in 2005). They also find that a large share of employment growth in the US was due to increased employment in

22 This definition was then used as the basis for measuring contingent and alternative work arrangements in the Contingent Worker Supplement (CWS), which was conducted in February of 1995, 1997, 1999, 2001, and 2005. BLS stopped conducting this supplement in 2005 until it was re-established once again in 2017. 
alternative work..$^{23}$ In addition to the questions about contingent and alternative work, Katz and Krueger (2016) examined questions about direct selling activities by respondents through an on-line intermediary as part of their main or secondary job and found that about 0.5 percent of all workers identified customers through an online intermediary.

In 2017, BLS conducted the Contingent Worker Supplement again, and Katz and Krueger (2019) use these data to compare to their earlier results from 2015 (Katz and Krueger 2016) and find that 10.1 percent of US workers in 2017 were employed in alternative work arrangements which was slightly lower than the 10.7 percent found in 2005. This new result using the 2017 CWS called into question their result from the 2015 RAND survey which showed large growth in alternative work arrangements between 2005 and 2015 (estimated at 15.8 percent in 2015). After further investigation into their 2015 results, Katz and Krueger (2019) conclude that their 2015 estimate overstated the percentage of workers in alternative work arrangements and that the higher incidence of alternative work arrangements found in the 2015 survey was due to cyclical labour market conditions, differences in survey methods, and oversampling of multiple job holders in the 2015 survey. One key difference in survey methods is the use of proxy respondents in the CWS, which was not done in the 2015 RAND survey. Katz and Krueger (2019) further conclude that the traditional survey questions to measure employment have difficulty capturing casual or intermittent work and miss many instances of multiple job holding.

Laß and Wooden (2019) measure non-standard employment in Australia using survey data from two surveys: the Australian Bureau of Statistics (ABS) Labour Force Survey and the Household Income and Labour Dynamics in Australia (HILDA) Survey. The authors define nonstandard employment as self-employed workers, contributing family workers, fixed-term employees, casual employees, other employees, and permanent part-time employees. Generally, casual employment would be difficult to identify, but given extensive regulation around casual employment, it is expected that casual employees in Australia will be able to self-identify and measures of casual employment are based on self-report data. However, the authors also identify casual employees as those responding that they do not receive paid annual or paid sick leave entitlements. Using these definitions, the results from both surveys indicate that less than half of the employed Australian workforce was in a standard employment relationship with a permanent, full-time job. Moreover, casual employment is the most prevalent form of nonstandard employment reported using either definition or either survey (between 20 and 25 percent).

Bracha and Burke (2016) use original survey data collected as part of the Federal Reserve Bank of New York's Survey of Consumer Expectations in December 2013, January 2015, and

\footnotetext{
${ }^{23}$ In addition to survey data, they also used administrative tax data (i.e., self-employment income filings from the US Internal Revenue Service) and found similar trends to that reported in their survey data.
} 
December 2015. The survey asks respondents about informal work done in the last 2 years as well as current informal work participation. ${ }^{24}$ Respondents are provided with a list of 15 informal paid activities or side jobs (e.g., babysitting, selling goods on websites) to which they respond "yes" or "no". ${ }^{25}$ While some of the informal activities are clearly done using online platforms, the survey also specifically asks if respondents use websites or mobile platforms to do or find work. Bracha and Burke (2016) define informal workers as those who reported being currently engaged in some type of informal activity with nonzero paid hours in those activities in a typical month. In this definition, they also generally excluded those reporting informal work that was exclusively related to renting out their own property or selling their own used goods. ${ }^{26}$ They then measure informal work in two ways: the percent of respondents engaged and the number of full-time job equivalents (using hours of work). They find that 37 percent of respondents over the age of 21 and not retired participated in informal work, though excluding those who only engaged in informal renting and selling activities, this dropped to 20 percent.

Bracha and Burke (2018) use the same survey data (with the inclusion of data collected in 2017) and definition of informal work from Bracha and Burke (2016) but now their definition of informal work is their definition of gig work. ${ }^{27}$ They measure gig work in terms of the participation rate, hours, and earnings. Their results indicate that in the US the percentage of respondents participating in gig work did not significantly change between 2015 and 2017; however, the typical number of hours spent in informal work declined significantly as did the aggregate amount of hours expressed in terms of full-time equivalent jobs. The results were similar when disaggregating by task, except for ridesharing activity, which increased significantly between 2015 and 2017. Moreover, the share of respondents participating in gig work involving use of the internet or mobile platforms increased by 30 percent during this period. On the other hand, their measure of participation in self-employment stayed stable over this same time period and their measure of participation in freelance work declined slightly. This illustrates how multiple measures of the gig economy are likely to be required in order to fully understand what is happening in this market, and that simple measures of self-employment may be too broad to detect changes.

In 2018, the Bank of Canada added questions about informal paid activities similar to those discussed in Bracha and Burke (2016), and using these data, Kostyshyna and Luu (2019)

\footnotetext{
${ }^{24}$ Questions about current work will be more accurate and allows for point in time estimates; however, it may also reflect seasonal labour market influences than questions asked over a longer time frame.

25 Respondents can also select an 'other' category where the activity is provided as free text.

${ }^{26}$ For this determination, the list of activities includes activities such as 1) "renting out property such as your car, your place of residence, or other items you own", 2) "driving for a ride sharing service like Uber, Lift, or Sidecar", 3) "selling goods at consignment shops, and 4) "selling goods on eBay, craigslist, or similar websites". For these activities, it is generally difficult to distinguish earnings derived from the value of the asset from the actual labour income. In addition, these are thought to be less labour intensive than other types of gig work (e.g., personal services). For these reasons, these activities are generally excluded. It is important to note, however, that similar issues may exist when trying to separate labour income from other income for working proprietors.

27 They exclude respondents whose only informal paid activity is responding to surveys.
} 
find that 66 percent of respondents in Canada reported being currently engaged in informal paid activities. This number dropped to 30 percent when excluding selling goods or renting property and to 18 percent when also excluding those who consider the activity to be a hobby.

Kostyshyna and Luu (2019) use a slightly different definition of informal work than that used by Bracha and Burke (2016). Whereas Bracha and Burke (2016) restrict their analysis to respondents aged 21 and above, non-retired, and reporting non-zero informal activity hours in a typical month, Kostyshyna and Luu (2019) do not. In addition to examining the participation rate, Kostyshyna and Luu (2019) calculate the number of FTE jobs as a share of the labour force. ${ }^{28}$

In the UK, a not-for-profit organisation, Chartered Institute of Personnel and Development, conducted an online survey, which was designed to inform a government-commissioned review about employment practices (CIPD 2017). ${ }^{29}$ The survey provides measures of gig workers, defined as individuals who used online platforms in the previous 12 months for any of the following activities: ${ }^{30}$

- to provide transport using their own vehicle,

- to rent out their own vehicle,

- to deliver food or goods,

- to perform short-term service jobs, or

- other work arranged through a platform.

The results of this survey indicate that approximately 4 percent of the working-age population (18-70) in the UK had engaged in any type of paid gig work, and that $58 \%$ of gig workers have permanent employment in addition to their gig work activities (CIPD 2017). According to the report, the survey was designed to be nationally representative and results were weighted based on social grade, region, gender, age, and ethnicity. The report, however, does not provide a response rate, nor does it provide a comparison between the sample population and the UK population.

Farrell et al. (2018) use 39 million JPMorgan Chase checking accounts in the US to track payments through 128 online platforms to 2.3 million families participating in the online platform economy between 2012 and 2018. They measure the size of the online platform economy as the fraction of families earning online platform income in a given time period (e.g., one year, one quarter, one month), ${ }^{31}$ and as the total transaction volume from these platforms

\footnotetext{
${ }^{28}$ In one measure, they restrict to those with the greatest labour force attachment who were most likely to switch to formal work.

${ }^{29}$ For more information about the review, see https://www.gov.uk/government/publications/good-work-the-taylorreview-of-modern-working-practices.

${ }^{30}$ Respondents using online platforms to sell goods or to rent out their property were excluded from the definition of gig worker.

31 The authors do not define this as measuring the gig economy. They indicate that contingent workers are more often thought of as the Gig Economy and their sample is only a subset.
} 
paid into the checking accounts of these families. They find that the fraction of families with online platform work in the past year grew from just under 2 percent to 4.5 percent in between 2013 and 2018, whereas, this fraction grew from 0.5 to 1.6 percent when looking at online platform work in the current month. Transaction volume also grew from approximately US $\$ 50$ million at the end of 2012 to almost US\$300 million in March 2018. Online platforms in the transportation sector appear to be driving these results, regardless of the measure. The results of this analysis also indicate that the majority of families earn income using online platforms for three or fewer months out of a year, but when they do participate, it is a major source of income. One problem with this sample is its representativeness of the overall population as a whole. For example, it over represents younger, male-headed families in the Western US. Hence, it is difficult to extrapolate from this population to the US economy as a whole. In addition, having the analysis at the family level makes it difficult to compare the findings with standard labour market measures.

Eurofound (2018) also examines different aspects of platform work, which is defined as paid work for which the supply and demand were matched through an online platform. The study is of 10 common types of platform work in the EU, which are based on the typology described previously. The focus is on three specific types: on-location platform determined work (low-skilled); on-location worker-initiated work (low- to moderate-skill); and online contest work (high-skilled). To learn more about these three specific types of platform work, platform workers of each type were interviewed. While the platform economy is not measured, the report provides findings consistent with the rest of the literature. First, platform work is not most workers' main activity; however, for some on-location types, it is their main activity. Second, earnings for all types are variable, but they are most variable for online contests. Earnings from on-location worker-initiated work are the most predictable.

\subsection{Different answers from different measures}

One issue with using these different types of data is that they can and often do provide differing results. Household surveys in the US tend to show a decline in self-employment rates (either using the main job or using any job) over the last decade; in contrast, administrative data tends to show an increase in these rates over the same time period (Abraham et al. 2018). Figure 1 from Abraham et al. (2018) shows the degree of discrepancy between estimates using survey data (lower lines in red) and administrative data (upper lines in black).

Katz and Krueger (2019) show the same discrepancy (see Figure 2), but using a longer time period than Abraham et al. (2018). Given the longer time frame, Katz and Krueger (2019) are also able to show that this gap has been widening over time from almost zero in 1980 . 
Figure 1: Self-employment rates using US household survey and administrative data

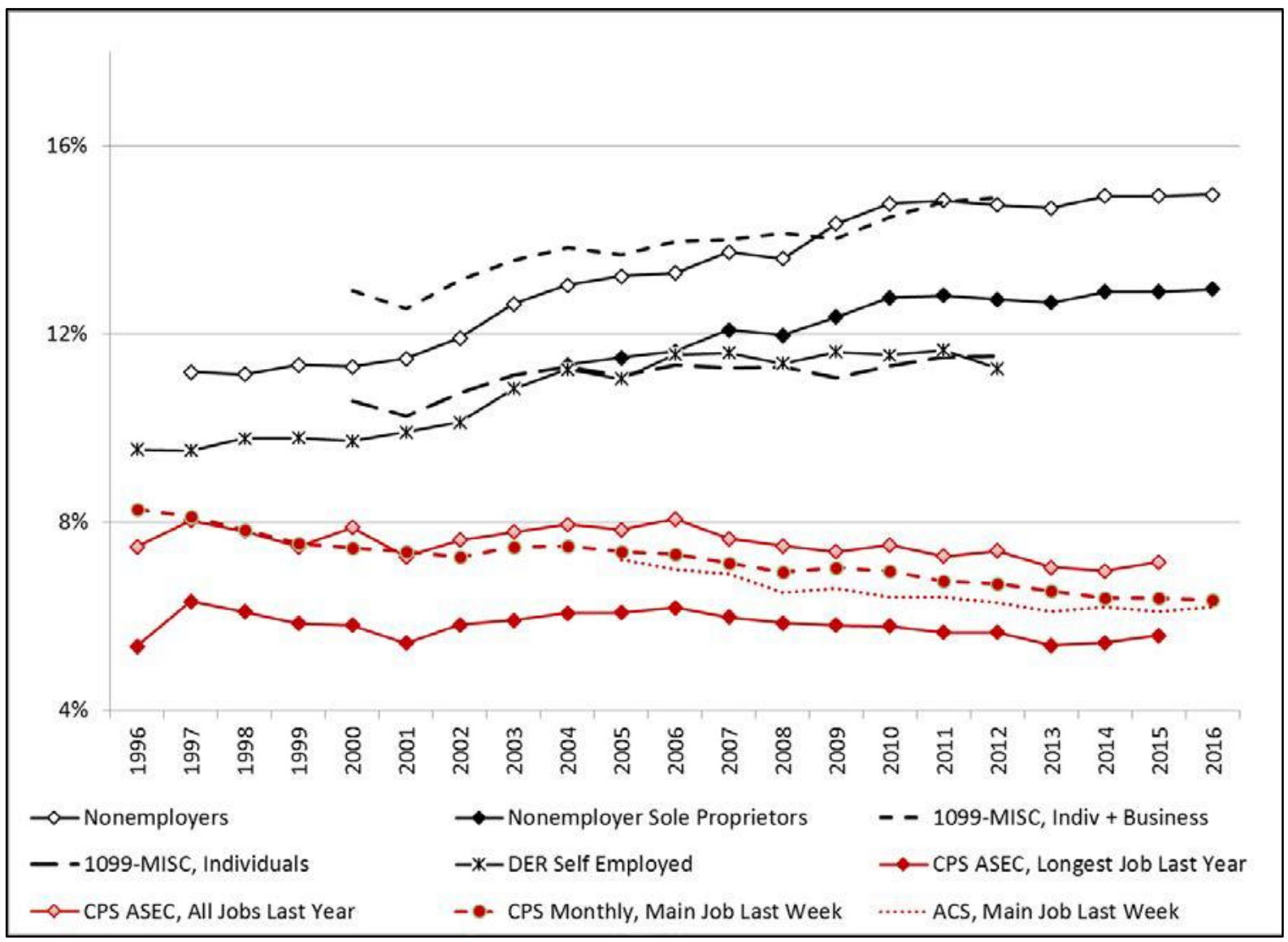

Source: Abraham et al. (2018). "Nonemployers" and "Nonemployer Sole Proprietors" are from the Census Bureau website. "1099-MISC, Indiv + Business" and "1099-MISC, Individuals" are from U.S. Department of Treasury (2015). "DER Self Employed” is authors' calculations from integrated CPS and DER data. "CPS ASEC, Longest Job Last Year" and "CPS ASEC, All Jobs Last Year" are authors' calculations from the public CPS-ASEC file. "CPS Monthly, Main Job Last Week' is from the BLS website. "ACS, Main Job Last Week" is from the Census Bureau website. 
Figure 2: Trends in US self-employment: household survey data vs. administrative data

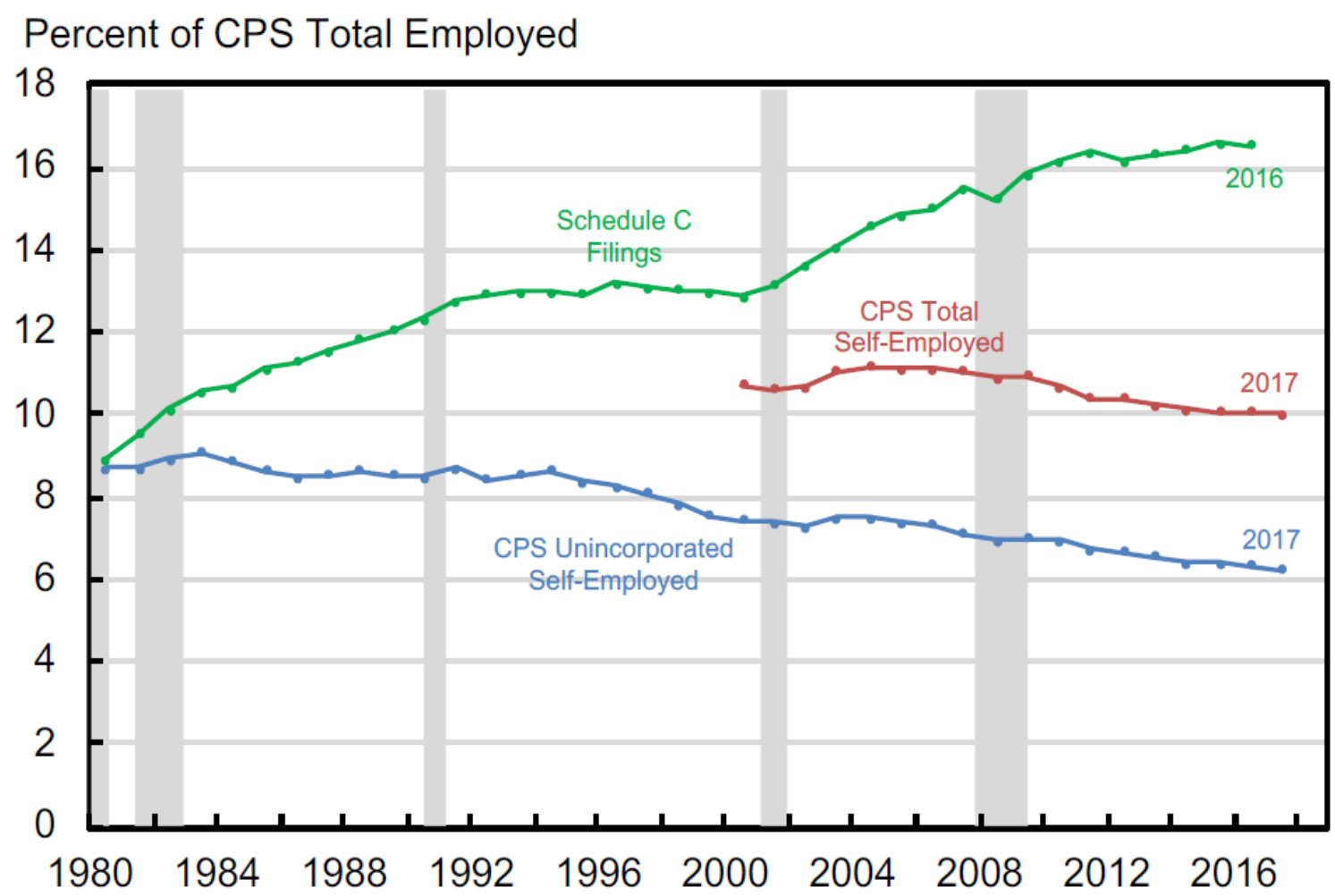

Source: Katz and Krueger (2019). Self-employment measures from Current Population Survey and Schedule C Filings from IRS Statistics of Income Publication 1304, Table 1.3.

Abraham et al. (2018) examine this discrepancy between administrative and survey data further by linking survey data to administrative data at the individual level in order to compare the information from the two sources for the same people. One of their key findings is that a majority of individuals categorised as self-employed using the survey data are not categorised as self-employed using the administrative data and vice versa, suggesting a degree of fluidity in reporting self-employment status. Hence, their conclusion is that neither data type may be ideally suited to capture all activity, but, when combined, the two sources may provide a more complete picture.

It is unclear which factors are driving the discrepancy. However, Katz and Krueger (2019) surveyed participants recruited from Amazon Mechanical Turk and, based on their analysis of the results, conclude that the basic Current Population Survey question on multiple job holding missed many instances of multiple job holding, most of which were tasks that came through the Amazon Mechanical Turk platform. Additional probing of respondents for other small paid jobs almost doubled the percentage of workers who were multiple job holders (from 39\% to 77\%).

Collins et al. (2019) use US tax data to identify contract work done by self-employed individuals for firms, including the subset of this work that is mediated by online platforms, in order to further examine the discrepancy between the results from administrative and survey 
data. Their results indicate that there has been explosive growth in work mediated by online platforms and that this growth has driven growth in the overall category of contract work. However, this type of work is not workers' primary source of income (making it difficult to pick up through household surveys). Moreover, for most workers who get work through online platforms, their earnings through these platforms are very small (less than US\$2500) and are supplemental to the workers' more traditional jobs. The authors also find that individuals were no more likely to work full-time in these types of jobs in 2016 than they were in 2005. In general, they find that moving towards a definition of full-time employment in either contract work or self-employment more generally reduces the growth rate.

\subsection{Recommendations for measures of gig work and the gig economy}

As has been shown in the literature, simple measures of self-employment are insufficient for accurately assessing what is happening in the gig economy. As Collins et al. (2019) show, dramatic growth in participation in online platform work is masked by changes in more traditional contract work, so the aggregate series may show little movement even though the underlying components are changing substantially. The extent to which this is true may depend on whether gig work is substituting for or complementary to traditional work. Moreover, much of the literature indicates that most gig work is done intermittently either to cover employees when they are between jobs or for additional earnings while also working in traditional employment. This is part of the reason why surveys asking about employment in the last week or about main/secondary jobs miss some gig work. Hence, measures of gig work need to go beyond traditional measures of self-employment.

Ideally, measures of gig work should be multi-faceted and easy to aggregate or disaggregate, given the variety of contexts in which these measures might be used. In addition, these measures should go beyond simply counting the number of people engaged in gig work and also include measures of the extent to which people engage in gig work (e.g., number of hours, income, transaction volume), and they should include multiple timeframes (e.g., current, previous month, previous 12 months). Survey questions such as those included in surveys by the Federal Bank of New York and by the Bank of Canada as described in Bracha and Burke (2016) and Kostyshyna and Luu (2019) would allow for multi-faceted, flexible measures of engagement as well as the extent of that engagement. Such measures would enable measurement of gig work at different breadths of definition, as required to answer a range of questions.

Alternatively, measures of gig employment could be obtained using current surveys used for traditional employment measures (e.g., the Household Labour Force Survey) with additional probing for informal work activity, especially when this information is provided by proxies for other members in the household. These surveys generally ask about work done by the respondent for pay or profit or about the respondent's jobs or businesses, yet respondents may 
not think about informal work activity in these respects. Abraham and Amaya (2018) and Katz and Krueger (2019) both find that these traditional questions fail to capture a substantial number of people involved in informal work and that additional probing can be used to mitigate this problem. Abraham and Amaya (2018) find that additional probing is particularly effective in capturing informal work activity from those reporting two or more jobs in response to the standard questions and also from proxies reporting on work activity by others in the household. While this type of probing may uncover informal work activities that would have gone unobserved in the past, the current research indicates that such probing is a key component of identifying gig work, especially when the work is done in addition to a person's main job.

\subsection{Data currently available in New Zealand}

Implementing or changing surveys takes time and is a longer-term solution. In the short term, however, it may be possible to develop some measures of alternative or informal work as proxies for gig work, while recognising their limitations. For example, the Household Labour Force Survey (HLFS) could be used for an analysis of non-standard work similar to that reported in Laß and Wooden (2019) using HLFS categories for employees (based on their main job), ${ }^{32}$ and for the self-employed (also based on the respondent's main job). ${ }^{33}$ Figure 3 shows the selfemployed can be differentiated as to whether or not they employ others; however, these measures may be too broad to adequately distinguish gig work from other work. Other limitations in using these data are similar to those previously discussed for measuring informal work using traditional surveys (e.g., missing informal activity when it is not a person's main job, using proxies). In addition, the HLFS redesign in 2016 directly impacts the measurement of the self-employed, ${ }^{34}$ making trend analysis difficult. This discontinuity can clearly be seen in Figure 4.

\footnotetext{
32 Employees are categorised as either permanent, casual, temporary agency, fixed-term, seasonal - permanent, seasonal - temporary, or temporary - type not further specified.

33 The self-employed are categorised as an employer, self-employed without employees, or unpaid family worker.

34 Prior to 2016, a filtering question led to an over count of employees and an undercount of the self-employed.
} 
Figure 3: Self-employment in New Zealand using HLFS
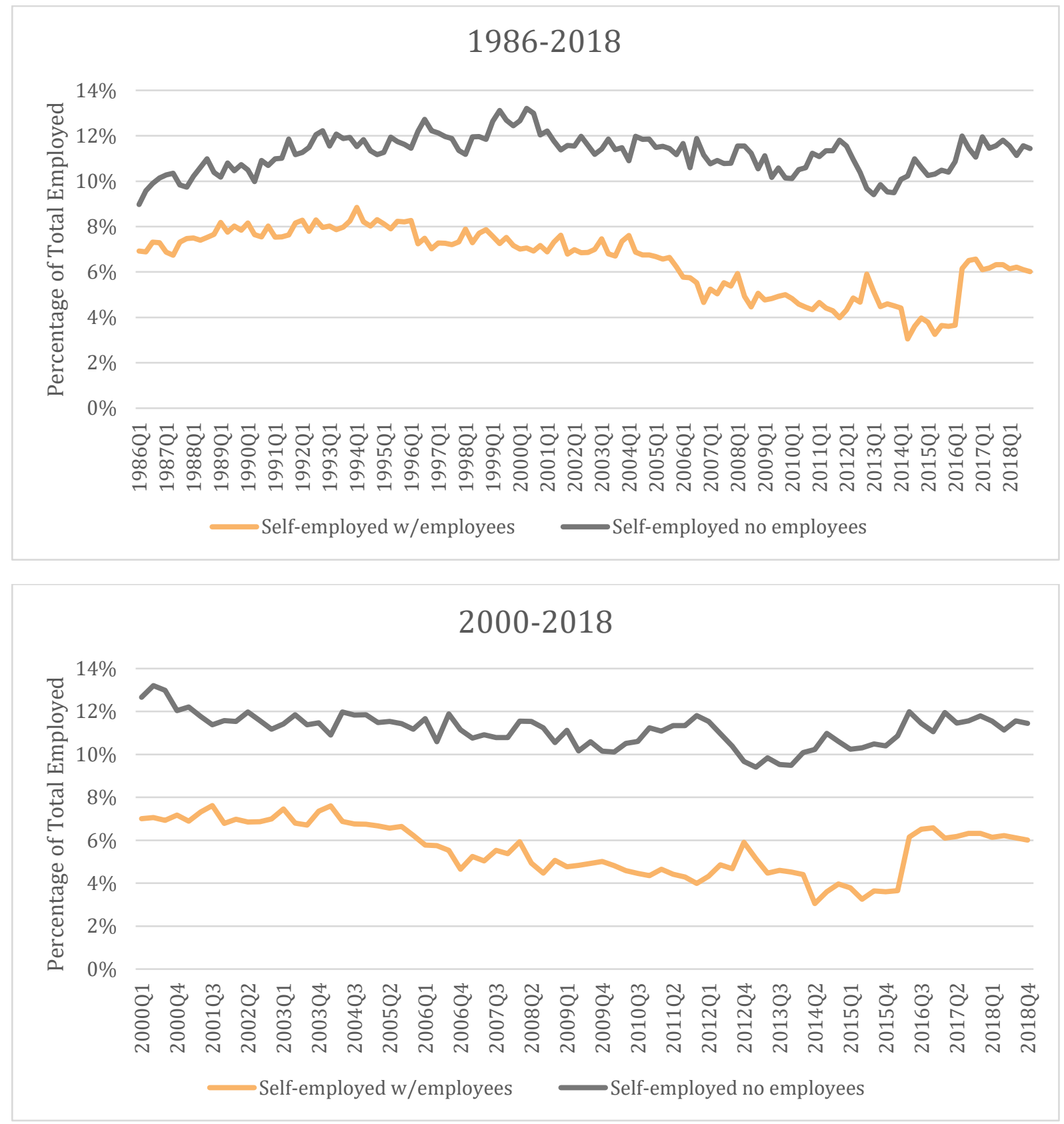

Source: Statistics New Zealand Household Labour Force Survey (Table reference: HLF001AA). The top panel shows the self-employment rate for those with and without employees from the first quarter of 1986 to the last quarter of 2018 and the bottom panel shows the same rates but from the first quarter of 2000 to the last quarter of 2018. Note also the discontinuity in 2016, which is particularly apparent in the series for the self-employed with employees. 
Figure 4: New Zealand employment types using HLFS

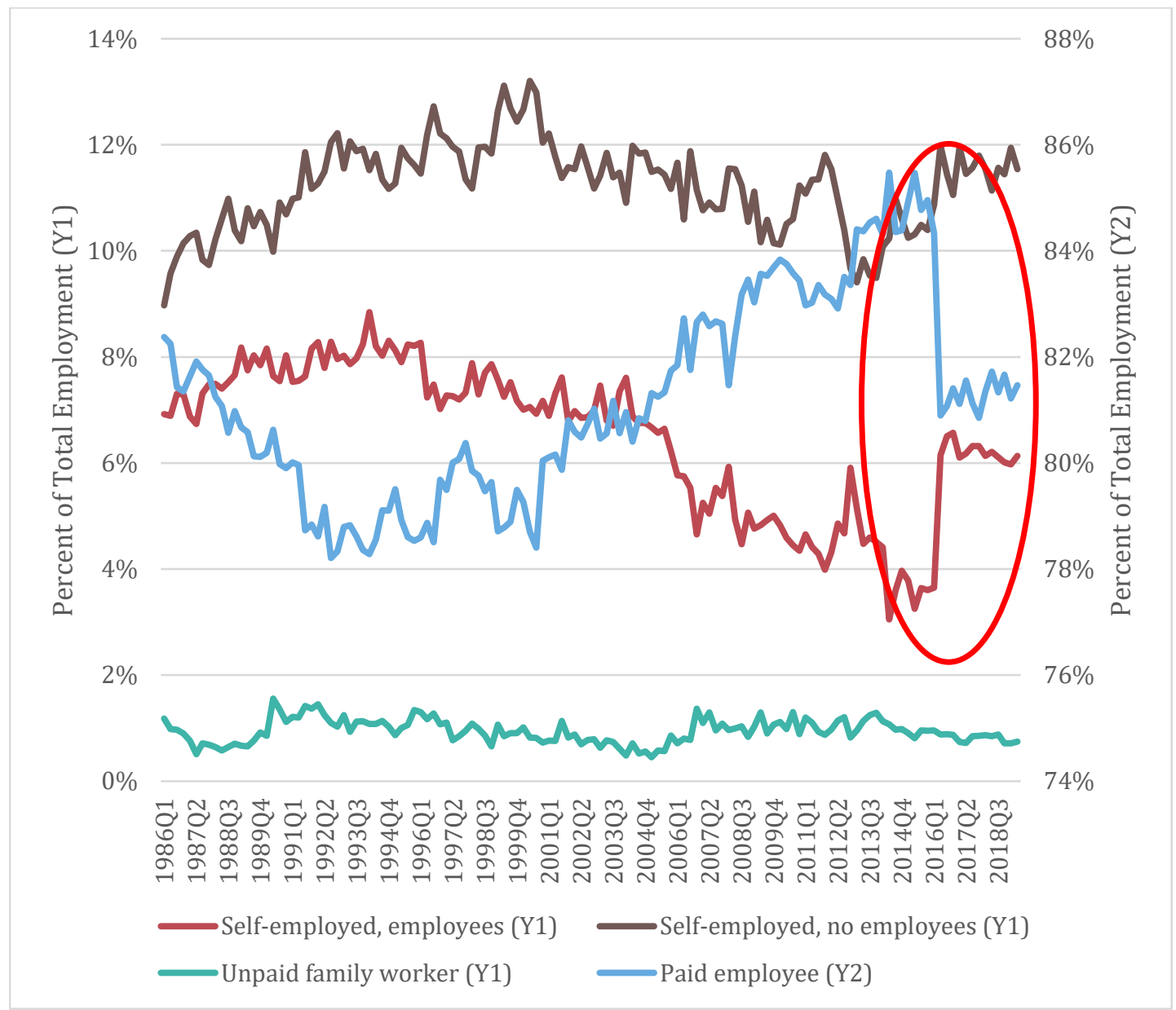

Source: Statistics New Zealand Household Labour Force Survey (Table reference: HLF001AA). The relationship between the percentage of the workforce that is self-employed with employees (orange line) appears to be inversely correlated with the percentage of the workforce that is employed (blue line) based on the respondent's main job. Showing the percentage of paid employees on the right vertical axis (Y2) with the other series plotted against the left vertical axis (Y1) allows the similarity in these lines to be seen more clearly. Note also the discontinuity in 2016 (within the red circle) which is particularly apparent in the series for the self-employed with employees relative to paid employees.

On the other hand, using a more dedicated supplement may be a better approach. One of the HLFS supplements, the Survey of Working Life, ${ }^{35}$ may provide better information to differentiate those with more precarious employment from more traditional employment. 
There are a number of relevant questions in this supplement that could help to differentiate gig work from other types of employment, including the following topics:

- written employment agreement for main job,

- contracting in main job (asked of the self-employed without employees) including questions about the nature of the work,

- employer provision of on-the-job training,

- predictable or regular schedule,

- annual leave entitlements,

- chance of losing job for reason beyond own control,

- multiple paid jobs, and

- income from main, second, and all jobs.

Even with these more detailed questions, this survey is likely to have the same issues with missing informal work activity due to people not equating these activities with a job or paid income.

Examining employment and income reported in the Household Economic Survey (HES) could also provide measures of alternative or informal work as proxies for gig work. For example, the HES includes measures of hobby and casual job income, other regular income, and irregular income - all categories that are likely to contain income from informal work. The HES also asks about the respondents' different jobs (or businesses), including the hours worked, when the job or business began, and the type of employment: self-employed not employing others, an employer of others in own business, permanent paid employee, fixed-term paid employee, working without pay in a family business or farm, or other type of working or payment arrangement. The HES also asks respondents if their employers contribute to their KiwiSaver scheme. The main limitation of using the HES would be the small sample size in historical data. ${ }^{36}$

Administrative data, typically tax data from IRD sources and made available by Statistics New Zealand, also allow for some measurement of alternative or informal work. For example, examining aggregate measures of business types that are more likely to represent the selfemployed (e.g., individual proprietorships, partnerships, zero-employee businesses) could be a place to start. However, in these aggregate measures of self-employment, there appears to be a disconnect between the trends in the survey data and different administrative data sources, though the 2016 discontinuity in the HLFS makes it difficult to assess the trend in selfemployment. From the HLFS, it appears that the number of self-employed with no employees has stayed relatively flat since the early 2000s. In contrast, the business demography statistics

\footnotetext{
36 Prior to the 2018/19 survey, the HES achieved sample was generally between 3,500 and 5,500 households. The recent redesign of the HES survey was intended to achieve a sample of 20,000 households.
} 
presented in Figure 5 show a clear downward trend since 2000 in individual proprietorships and partnerships as proportions of total businesses.

Figure 5: New Zealand businesses by business type using business demography statistics

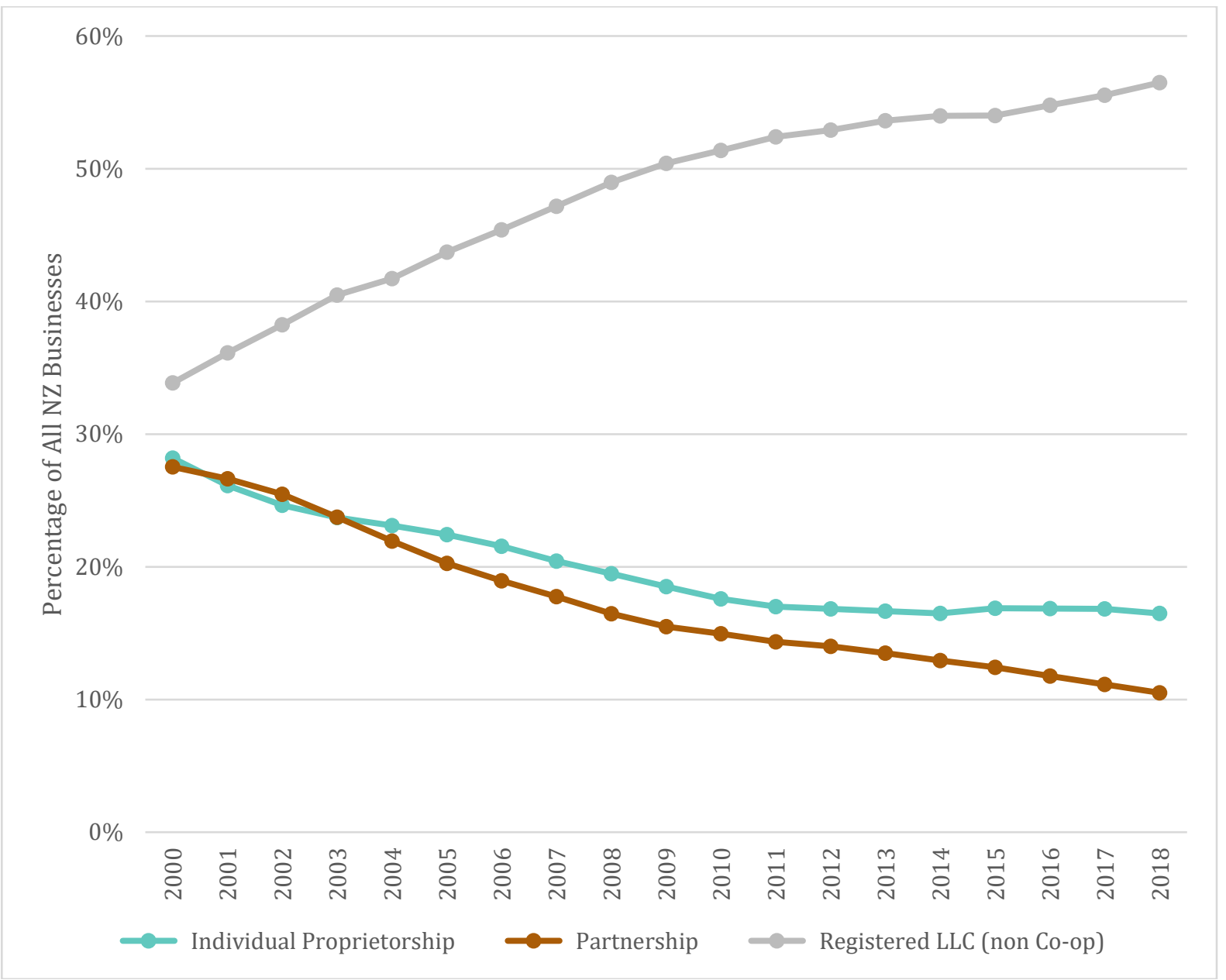

Source: Statistics New Zealand Business Demography Statistics. This figure shows that the two types of businesses typically associated with self-employment - individual proprietorships and partnerships have been declining as a percentage of all New Zealand businesses, while the percentage of registered LLCs has been increasing. However, the business demography statistics are generally expected to undercount small businesses.

Businesses with zero employees, on the other hand, have become an increasing proportion of all businesses. This is also true for LLCs, individual proprietorships, and partnerships as shown in Figure 6. Those with zero employees increased from 66 percent to 70 percent of all businesses between 2000 and 2018; they increased from 80 percent to 90 percent of individual proprietorships over this same time period; and they increased from 51 percent to 59 percent of registered LLCs. 
Figure 6: New Zealand zero-employee businesses using business demography statistics

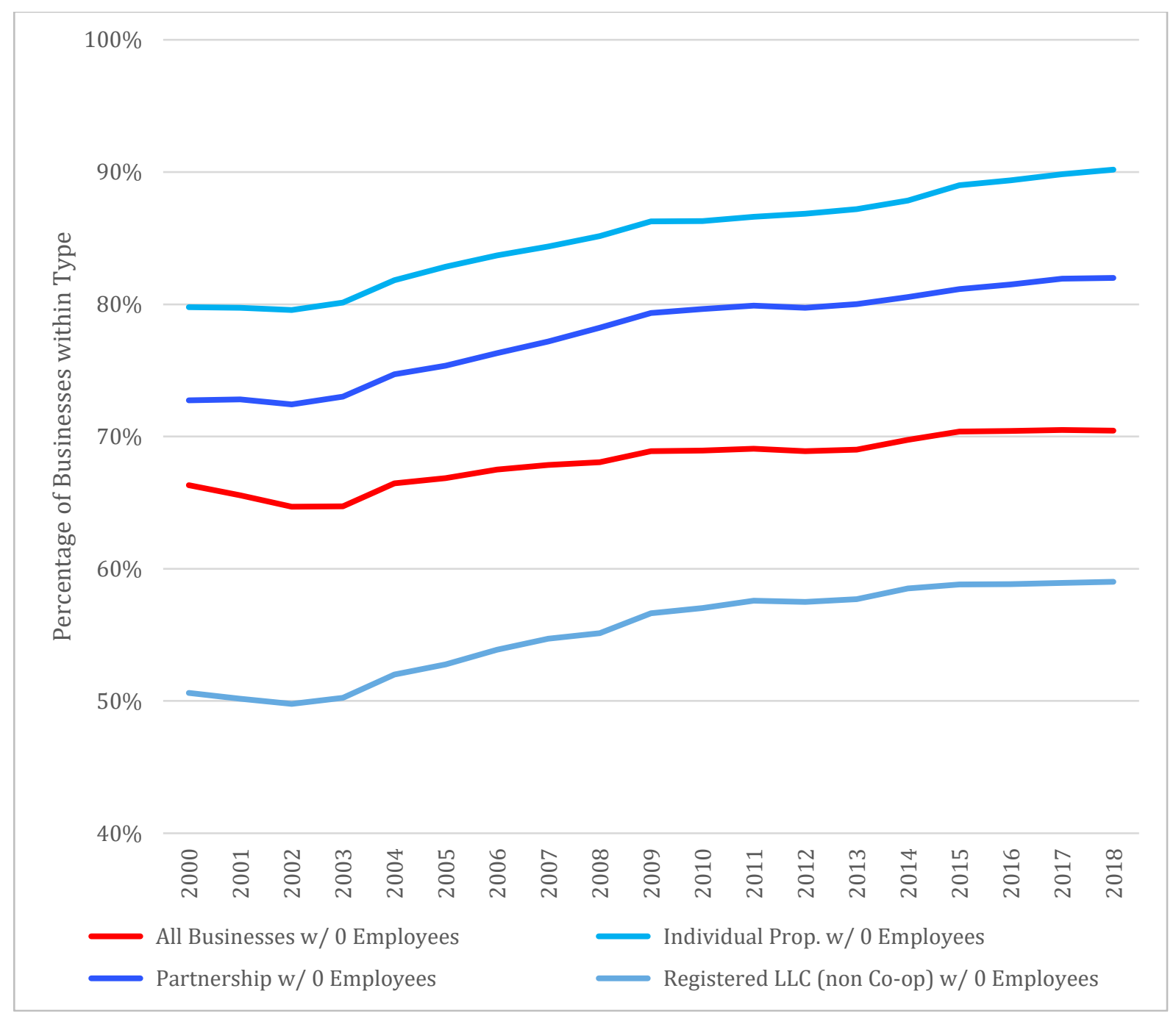

Source: Statistics New Zealand Business Demography Statistics. In this figure, zero-employee businesses in New Zealand are an increasing percentage of all businesses. However, the employee count data may or may not count working owners, depending on whether or not the working owner paid themselves a salary or wage subject to PAYE. Working owners paid a salary or wage subject to PAYE are counted as employees, which would put these businesses into the 1-5 employee category. Moreover, not all businesses have a working owner, but these businesses are not distinguishable from those with a working owner in these statistics. The Business Demography Statistics also tend to underrepresent small businesses. Hence, trends in these data may not be representative of trends in gig work.

Some of the discrepancies between these different aggregate measures are likely due to differences in coverage or definitions, and a number of caveats are required when thinking about the meaning of these trends for the gig economy. For example, the HLFS generally relies on categorising respondents using their main job, though the literature indicates that gig work tends to be in addition to their main job. The Business Demography Statistics population may also limit its applicability to gig work more generally. First, the Business Demography Statistics are limited to economically significant enterprises with limited coverage of small enterprises, and some zero-employee businesses may not have a working proprietor. Second, the employee 
counts in the business demography statistics may or may not count the business owner as an employee. Hence, these trends do not necessarily identify trends in gig work and should be treated with caution. To really understand gig work, an examination of the underlying microdata is needed.

Fabling and Maré (2015) use administrative microdata to identify working proprietors (e.g., the self-employed). ${ }^{37}$ In their analysis, they show that the share of individuals who are working proprietors declines between 2000 and 2013 (from 19.2 to 12.9 percent) and that the share of working proprietors who also have another job declines over this same time period (from 6.3 to 3.0 percent).

The methodology Fabling and Maré (2015) use to identify working proprietors is as follows:

- sole proprietors who pay themselves PAYE income, which is identified using the Employer Monthly Schedule from Inland Revenue where the payer number is the same as the payee number;

- sole proprietors with non-zero self-employment income from box 23 of the IR3;

- partners with partnership income from box 25J of the IR7P but excluding passive investor partners (whose income would purely be from capital investment) identified as those reporting this income in box 24 of the IR3 rather than in box 18B of the IR3 where active partnership income is reported; 38

- company owners receiving income with no PAYE deducted as reported in box 41C of the IR4S with earnings greater than $\$ 15,000$ in at least one year (in real 2000 dollars). ${ }^{39}$

From these data, measures of the number of working proprietors in terms of head count and FTE can be used. To more finely separate gig workers from the self-employed may require additional information, though it would be possible to link to individuals in the survey data mentioned above to examine where there may be gaps in both the administrative data and the survey data.

The methodology used in Fabling and Maré (2015) to identify working proprietors could also be used to identify relevant income, though they do not attempt to use income to determine the labour share of working proprietors precisely because of the difficulty in distinguishing the labour share of income from the return-to-capital. Moreover, the data they use from the IR3 and IR7P are net income measures. By combining tax information about income and expenses,

\footnotetext{
37 The data they developed using this methodology are available to researchers through Statistics New Zealand's data labs.

38 The box numbers are with respect to the 2012 version of the form. Fabling and Maré (2015) report that this distinction is due to ACC levies being based on active partnership income.

39 The box numbers are with respect to the 2012 version of the form. Also, income reported in box 41C of the IR4S includes shareholders, directors, and relatives of shareholders which may lead to overcounting working proprietors; hence, the restriction to earnings greater than $\$ 15,000$ is to exclude those who are likely to not be working proprietors but may still include some passive investors.
} 
however, it may be feasible to roughly estimate total revenue in these cases. Relevant expenses are likely to be reported on the IR3B, IR3F, the IR3R, or the IR10, but reporters also have the option to submit their own financial records to provide further detail, and this information is likely not included in the data available to researchers. It should also be noted that the IR3 and IR7P both capture rental income separately, and the IR3R when submitted provides information on total rents as well as specific information on expenses (e.g., rates, insurance, interest, repairs and maintenance, agents' fees, other). Using these data in combination with GST receipts for zero-employee businesses and working proprietors could provide more information about the volume of transactions conducted. 40

Fabling and Maré (2015) report that between 3 percent and 6.3 percent of working proprietors also have a job as an employee elsewhere in any given year, though it is unclear if the employment in both occurs simultaneously or if this represents transitions between employment and self-employment. They also measure short spell jobs (two months or less) and gaps in employment for employees using the Employer Monthly Schedule. Given the intermittent nature of gig work and the reported use of it when workers are between jobs, it may be useful to examine these short spell jobs and gaps along with self-employment income reported in the tax data to identify potential gig workers, though this analysis will be complicated by the fact that self-employment income is reported on an annual basis and the exact timing of the income receipt is unknown. Still, examining trends in self-employment income for employees with gaps or short spell jobs in their employment history may provide some insights. For example, if employees with gaps in their employment history also report self-employment income only for that year, this pattern would be indicative of employees using gig work to supplement their income when they are between jobs. On the other hand, employees reporting self-employment income in years without gaps or short jobs spells are more likely to be using gig work to top up their income.

Administrative or survey data can be used to measure income for the self-employed, but, as discussed previously, it is difficult to measure labour income for this group because income is not always defined separately from expenses or from the share of the income generated by an individual's assets. This is most relevant for the self-employed leveraging their own assets for their work (e.g., AirBnB owners, Uber drivers using their own cars). Bracha and Burke (2018) use two measures of gig work: a broad measure that excludes gig work that consists of responding to surveys and a narrower measure that also excludes renting out respondents' own property or selling goods. Their rationale for the latter exclusion is that these activities are less labour-intensive than other gig work and that revenues from these activities may largely be based on the value of the assets.

\footnotetext{
40 It is unclear how much informal activity would be captured given the $\$ 60,000$ threshold for required registration
} for GST 
Capturing more information about assets and expenses may be possible using the IR10 (Financial Statements Summary) provided to IR by businesses and the self-employed in lieu of filing a full set of financial accounts. ${ }^{41}$ Since larger businesses tend to file their full financial accounts, IR10 data in the IDI tends to primarily be comprised of small businesses (Fabling and Sanderson 2016). It will still be difficult to determine labour income, but these data could provide a better sense of expenses paid and assets used by the self-employed.

For some contract work, contractors are required to provide form IR330C to the business for which they are working. The business then deduct tax from the contractors' payments and pay the tax directly to IR. The form IR330C should also include the schedular payment activity (e.g., freelance contributions, entertainment). This form is currently kept on file by the business paying the contractor, but if this information were reported to IR, it may provide additional information about some forms of gig work, and could be used in conjunction with the related schedular payments and deducted tax amounts as reported to IR via the employer monthly schedule.

\subsection{Next steps}

The first step in this process should be to build upon the work arrangements in Table 2 to further define gig work and to develop a taxonomy for measuring gig work in New Zealand that takes into account the potential uses for these measures and those aspects of the labour market that are specific to New Zealand. ${ }^{42}$ This taxonomy could then be used to develop measures of gig work and the gig economy. As discussed previously, measures of gig work ideally would be multi-faceted and easy to aggregate or disaggregate to address a broad array of applications. These measures should go beyond simply counting the number of people engaged in gig work and also include measures of the extent to which people engage in gig work (e.g., number of hours, income, transaction volume), and they should include multiple timeframes (e.g., current, previous month, previous 12 months).

The next step would be to analyse existing survey and administrative confidential microdata - as opposed to using publicly available aggregate data as we used in Section 4.4 taking into consideration the development of measures based on the new taxonomy. We can hypothesize about the suitability of existing data for these measures, but this is really an empirical question to ensure, for example, that sample sizes are sufficient. Moreover, this analysis could demonstrate gaps in coverage or potential areas of concern (e.g., reliance on proxies for respondents' data collection). One current gap is the lack of data for work hours in administrative data. The HLFS contains information about hours of work, but this information is

\footnotetext{
${ }^{41}$ In the IR3 Individual Return Guide, filers are given the option of filing their financial records, an IR3F, an IR3B, or an IR10.

42 Ideally, these measures would still be comparable to international measures, though there may be a trade-off between the degree of international comparability and the specificity of the New Zealand context.
} 
available for only a small percentage of the overall population. Proprietary data from private entities (e.g., financial institutions, platforms), to the extent it is made available, could also be used to further assess the limitations of existing survey and administrative data, though relying on this type of data for national measures would need to be carefully considered for the reasons discussed previously.

Once the taxonomy is developed and the analysis of existing data is completed, agencies should think about changing existing surveys or implementing new ones using the literature as a guide. The existing literature indicates that collecting information beyond a respondent's main or secondary job and additional probing of respondents yields more information about gig work that may otherwise be overlooked. Moreover, relying on proxies to provide information about gig work for others in the household can be problematic, so re-evaluating the extent to which proxies are used to collect this information may be warranted. Finally, questions such as those used by Bracha and Burke (2016) or CIPD (2017) allow for multi-faceted measures that can be easily aggregated as needed to address the question at hand and provide a guide for new survey questions that could be added to existing surveys. Hence, these questions could be used as a template for developing new questions.

Changes to administrative data collection would likely be onerous, but a first step here may be to evaluate the data that is provided for research compared to the data that is already collected. It may be possible that data currently being collected would be helpful in measuring gig work but may require additional approvals before it could be used for research purposes.

\section{Conclusions}

Most of the research done previously on this topic focuses on determining whether the gig economy is growing, and hence, if it should be a cause for concern. However, measuring the gig economy has proven difficult because gig work is not being fully captured by normal means and because there is little agreement on what actually constitutes gig work. The measures of the gig economy that have been used in the literature are very sensitive to the types of work arrangements included in the analysis as well as to the type of data used for the analysis. Hence, any measure should be developed with great care and consideration. Moreover, measures of gig work should be multi-faceted and easy to aggregate or disaggregate given the variety of contexts in which they might be used. 


\section{References}

Abraham, Katharine G, and Ashley Amaya. 2018. "Probing for Informal Work Activity." Working Paper 24880. National Bureau of Economic Research. https://doi.org/10.3386/w24880.

Abraham, Katharine G, John C Haltiwanger, Kristin Sandusky, and James R Spletzer. 2018. "Measuring the Gig Economy: Current Knowledge and Open Issues.” Working Paper 24950. National Bureau of Economic Research. https://doi.org/10.3386/w24950.

Bracha, Anat, and Mary A. Burke. 2016. "Who Counts as Employed?: Informal Work, Employment Status, and Labor Market Slack." SSRN Scholarly Paper ID 2935535. Rochester, NY: Social Science Research Network. https://papers.ssrn.com/abstract=2935535.

-_- 2018. The Ups and Downs of the Gig Economy, 2015-2017. http://ezproxy.auckland.ac.nz/login?url=https://search-proquestcom.ezproxy.auckland.ac.nz/docview/2189166064?accountid=8424.

CIPD. 2017. "To Gig or Not to Gig? Stories from the Modern Economy." Chartered Institute of Personnel and Development.

Collins, Brett, Andrew Garin, Dmitri Koustas, and Mark Payne. 2019. "Is Gig Work Replacing Traditional Employment? Evidence from Two Decades of Tax Returns." SOI Working Paper. https://www.irs.gov/pub/irs-soi/19rpgigworkreplacingtraditionalemployment.pdf.

Davidson, Nestor M., and John J. Infranca. 2016. "The Sharing Economy as an Urban Phenomenon." Yale Law \& Policy Review 34 (2): 215-79.

Eurofound. 2018. "Employment and Working Conditions of Selected Types of Platform Work." Luxembourg: Publications Office of the European Union. https://www.eurofound.europa.eu/sites/default/files/ef_publication/field_ef_document/ef1800 1en.pdf.

Fabling, Richard, and David Maré. 2015. "Addressing the Absence of Hours Information in Linked Employer-Employee Data." 15-17. Motu Working Paper.

Fabling, Richard, and Lynda Sanderson. 2016. “A Rough Guide to New Zealand's Longitudinal Business Database (2nd Edition).” Motu Working Paper 16-03. Motu Working Paper. Motu Economic and Public Policy Research.

Farrell, Diana, Fiona Grieg, and Amar Hamoudi. 2018. "The Online Platform Economy in 2018: Drivers, Workers, Sellers and Lessors." JPMorgan Chase Institute.

Freeman, Rebecca Ann. 2011. "Accounting for the Self-Employed in Labour Share Estimates: The Case of the United States.” 2011/04. OECD Science, Technology and Industry Working Papers. Paris: OECD Publishing. https://doi.org/10.1787/5kg0w877vlwg-en.

Gollin, Douglas. 2002. “Getting Income Shares Right.” Journal of Political Economy 110 (2): 458-74.

Gomis, Roger. 2019. “The Global Labour Income Share and Distribution: Methodological Description.” Geneva, Switzerland: International Labour Office. https://www.ilo.org/ilostatfiles/Documents/Labour\%20income\%20share\%20and\%20distribution.pdf.

Hall, Christie, and William Fussey. 2018. "Will Employees and Contractors Survive in the Gig Economy?” New Zealand Law Society. March 29, 2018. https://www.lawsociety.org.nz/practiceresources/practice-areas/employment-law/will-employees-and-contractors-survive-in-the-gigeconomy.

Katz, Lawrence F, and Alan B Krueger. 2016. "The Rise and Nature of Alternative Work Arrangements in the United States, 1995-2015." Working Paper 22667. National Bureau of Economic Research. https://doi.org/10.3386/w22667.

_-_. 2019. "Understanding Trends in Alternative Work Arrangements in the United States." Working Paper 25425. National Bureau of Economic Research. https://doi.org/10.3386/w25425.

Kenney, Martin, Petri Rouvinen, and John Zysman. 2018. "Employment, Work, and Value Creation in the Era of Digital Platforms." 2018-9. Berkeley Roundtable on the International Economy (BRIE) Working Paper. https://brie.berkeley.edu/sites/default/files/brie_working_paper_2018-9.pdf. 
Kostyshyna, Olena, and Corinne Luu. 2019. The Size and Characteristics of Informal ("Gig") Work in Canada. http://ezproxy.auckland.ac.nz/login?url=https://search-proquestcom.ezproxy.auckland.ac.nz/docview/2186320553?accountid=8424.

Krueger, Alan B. 1999. “Measuring Labor's Share.” American Economic Review 89 (2): 45-51.

Laß, Inga, and Mark Wooden. 2019. "Non-Standard Employment and Wages in Australia." Low Wage Growth Conference. Reserve Bank of Australia. https://www.rba.gov.au/publications/confs/2019/pdf/rba-conference-2019-lass-wooden.pdf.

Polivka, Anne E. 1996. "Contingent and Alternative Work Arrangements, Defined." Monthly Labor Review, October, 3-9. 


\section{Recent Motu Working Papers}

All papers in the Motu Working Paper Series are available on our website https://motu.nz, or by contacting us on info@motu.org.nz or +64 49394250.

19-17 Grimes, Arthur and Dominic White. 2019. Digital inclusion and wellbeing in New Zealand."

19-16 Maré, David C and Richard Fabling. 2019. “Competition and productivity: Do commonly used metrics suggest a relationship?"

19-15 Hall, Viv B and C John McDermott. 2019. “Changes in New Zealand's Business Insolvency Rates after the Global Financial Crisis."

19-14 Hyslop, Dean, Trinh Le, David C Maré and Steven Stillman. 2019. "Housing markets and migration Evidence from New Zealand."

19-13 Coleman, Andrew. 2019 "Liquidity, the government balance sheet, and the public sector discount rate."

19-12 Winchester, Niven, Dominic White and Catherine Leining. 2019. "A community of practice for economic modelling of climate change mitigation in New Zealand."

19-11 Fleming, David A., Suzi Kerr and Edmund Lou. 2019. "Cows, cash and climate: Low stocking rates, high-performing cows, emissions and profitability across New Zealand farms."

19-10 Cortés-Acosta, Sandra, David A. Fleming, Loïc Henry, Edmund Lou, Sally Owen and Bruce Small. 2019. "Identifying barriers to adoption of "no-cost" greenhouse gas mitigation practices in pastoral systems."

19-09 Kerr, Suzi, and Catherine Leining. 2019. 'Paying for Mitigation: How New Zealand Can Contribute to Others' Efforts."

19-08 Kerr, Suzi, and Catherine Leining. 2019. "Uncertainty, Risk and Investment and the NZ ETS."

19-07 Leining, Catherine and Suzi Kerr. 2019. 'Managing Scarcity and Ambition in the NZ ETS."

19-06 Grimes, Arthur, Kate Preston, David C Maré, Shaan Badenhorst and Stuart Donovan. 2019. "The Contrasting Importance of Quality of Life and Quality of Business for Domestic and International Migrants."

19-05 Maré, David C and Jacques Poot. 2019. "Valuing Cultural Diversity."

19-04 Kerr, Suzi, Steffen Lippert and Edmund Lou. 2019. "Financial Transfers and Climate Cooperation."

19-03 Fabling, Richard and David C Maré. 2019. "Improved productivity measurement in New Zealand's Longitudinal Business Database."

19-02 Sin, Isabelle and Judd Ormsby. 2019. "The settlement experience of Pacific migrants in New Zealand: Insights from LISNZ and the IDI"

19-01 Benjamin Davies and David C Maré. 2019. "Relatedness, Complexity and Local Growth.”

18-16 Hendy, Jo, Anne-Gaelle Ausseil, Isaac Bain, Élodie Blanc, David Fleming, Joel Gibbs, Alistair Hall, Alexander Herzig, Patrick Kavanagh, Suzi Kerr, Catherine Leining, Laëtitia Leroy, Edmund Lou, Juan Monge, Andy Reisinger, Jim Risk, Tarek Soliman, Adolf Stroombergen, Levente Timar, Tony van der Weerdan, Dominic White and Christian Zammit. 2018. "Land-use modelling in New Zealand: current practice and future needs."

18-15 White, Dominic, Niven Winchester, Martin Atkins, John Ballingall, Simon Coates, Ferran de Miguel Mercader, Suzie Greenhalgh, Andrew Kerr, Suzi Kerr, Jonathan Leaver, Catherine Leining, Juan Monge, James Neale, Andrew Philpott, Vincent Smart, Adolf Stroombergen, and Kiti Suomalainen. 2018. "Energy- and multi-sector modelling of climate change mitigation in New Zealand: current practice and future needs."

18-14 Preston, Kate, David C Maré, Arthur Grimes and Stuart Donovan. 2018. "Amenities and the attractiveness of New Zealand cities." 


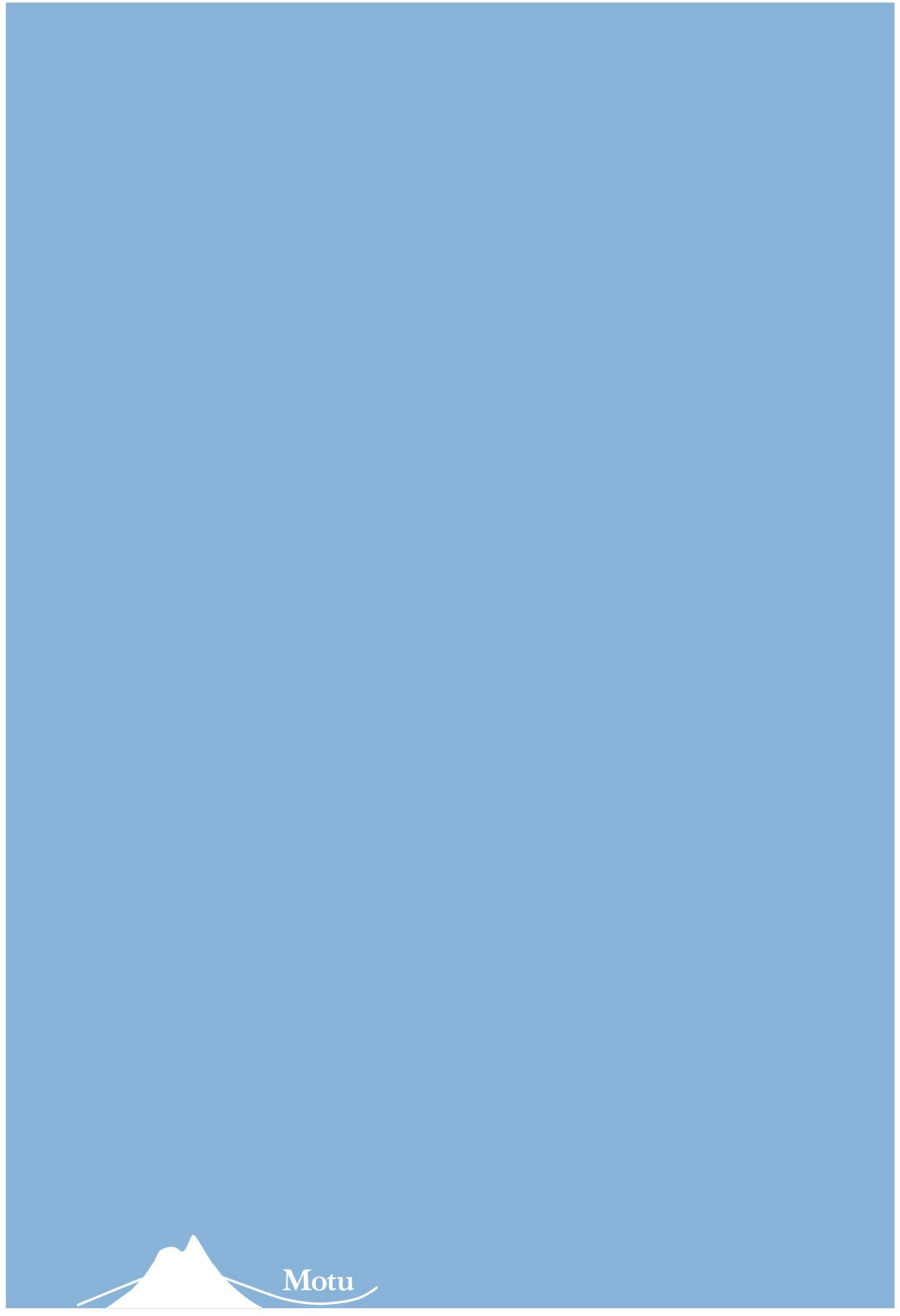

